\title{
Increased Catalytic Activity of Iron Phthalocyanine on the Electrochemical Nitrite Reduction upon Heat-Treatment Probed by X-ray Absorption Fine Structure
}

\author{
Sunghyun Kim* and Gwanghoon Kwag* \\ Department of Chemistry, Konktk Lniversity, Seoul 143-701, Korea \\ -Kumho Chemical Laboratories, Korea Kumho Petrochemical Companv: Taejon 305-600, Korea \\ Recerved August 28, 2001
}

Keywords : FePc. Heat-treatment. Nitrite reduction. XAFS. Electrocatalyst.

As nitrite is involved in many environmental aspects ${ }^{1}$ and it plays inportant physiological roles in the form of $\mathrm{NO}^{2-4}$ the detection of nitrite has been the subject of intensive research. Since the overpotential of nitrite reduction at ordinary solid electrodes is very high. much effort has been directed to look for better electrocatalysts. Meyer of al ${ }^{5-7}$ found that some metal complexes such as Ru(II)- Fe(II)EDTA and Fe(III)-porphyrin displayed high activities when dissolved in solution.

Our ongoing interest is to develop good electrochemical systems for the nitrite detection. We have reported that FePc shows an electrocatalytic activity on an electrode surface ${ }^{\S}$ or in a silica nuatrix prepared by sol-gel techniques. ${ }^{5}$ One of the main problents of $\mathrm{FePc}$ on the surface is its instability. Under harsh environment $\mathrm{FePc}$ easily loses its activity. ${ }^{10}$ One way of overcoming this problem is to treat $\mathrm{FePc}$ at high temperatures. Heat-treatment has been used as a way of imparting thermal and mechanical stabilities to the supported electrocatalysts since the discovery of the beneficial effect by Jahnke et al.." This method has been applied to transition metal complexes with porphyrin or phthalocyanine ligand as substitutes for platinum for the oxygen reduction in a fuel cell. It is generally believed that metal- $\mathrm{N}_{4}$ moiety forms at low heat-temperatures while small metal clusters forms at high heat-temperatures. Recently other explanations. in which $\mathrm{FeN}_{2} \mathrm{C}_{4}^{+}$may be the active site, have been suggested. ${ }^{\text {: }}$

In this paper, we present our results on the heat-treatment effect of supported FePc on the electrochemical reduction of nitrite. We also monitored the structural alteration of FePc brought by heat-treatment by X-ray absorption fine structure (XAFS) and related it to the catalytic activity.

Electrochemical behaviors of FePc before and after heat treatment, and corresponding nitrite reduction in $0.5 \mathrm{M}$ $\mathrm{H}_{2} \mathrm{SO}_{4}$ containing $5.0 \mathrm{mM} \mathrm{NO}{ }_{2}^{-}$were exanined by cyclic voltanumetry (Figure I). Two redox peaks I and II are largest for a nonheat-treated sample and gradually beconte smaller as heat-treatment temperature increases. implying structural alteration takes place. The peak I is responsible for the nitrite reduction but rapidly disappearing upon heat-treatment. It is noticeable that the nitrite reduction activity gradually increases with heat-treatment temperature and reaches the maxinum at $800^{\circ} \mathrm{C}$ (Figure 2). Temperature was raised at

'Corresponding author: Tel: +82-2-450-3378, Fax: +82-2-4562744; E-mail: skim 100akonkuk ac.ks

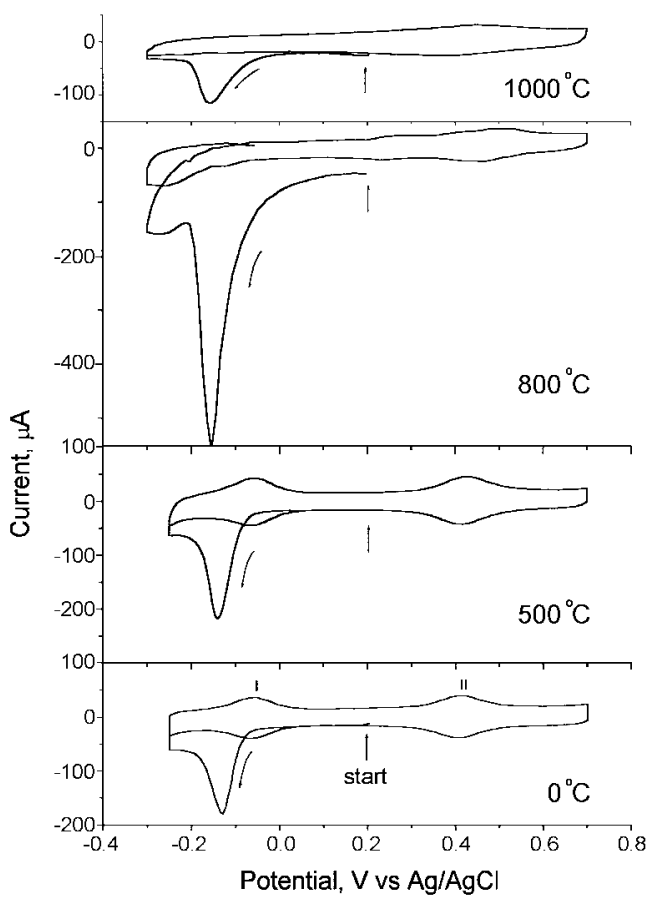

Figure 1. Cyclic voltammetry of supported $\mathrm{FePc}$ on high area carbon and nitrite reduction in $0.5 \mathrm{M} \mathrm{H}_{2} \mathrm{SO}_{4}$ by undeat-treated and heat-treated samples at 500,800 , and $1000^{\circ} \mathrm{C}$. $\left[\mathrm{NO}_{2}^{-}\right]=5 \mathrm{mM}$; scan rate $=10 \mathrm{mVs}^{-1}$.

$10^{\circ} \mathrm{C} \mathrm{min}^{-1}$ to the desired value and maintained for 2 lurs. The activity at $800^{\circ} \mathrm{C}$ is about three times higher than that of untheat-treated sample. XANES analyses (data not shown) shows that fine structures due to $\mathrm{ls} \rightarrow 4 \mathrm{p}$ transitions. characteristics of $\mathrm{FePc}$, rapidly disappear above $600^{\circ} \mathrm{C}$ and metallic iron features begin to appear, indicating that the square planar geometry of Fe- $\mathrm{N}_{4}$ is not maintained. This indicates that heat-treatment at high temperature causes the decomposition of Fe $-\mathrm{N}_{4}$ to metallic Fe. The similar phenomenon was observed in cobalt porphyrin and phthalocyanine. ${ }^{13.14}$ Detailed structural information can be obtained from Fourier transformed spectra of EXAFS (Figure 3). Well-defined Fe- $\mathrm{N}_{\mathrm{p}}$ and $\mathrm{Fe}-\mathrm{C}$ shells at 1.57 and $2.57 \AA$ (phase-shift uncorrected) were observed for the unheattreated sample. indicating adsorption itself does not induce structural alteration. Upon heat-treatment a new peak began to grow at $c a .2 .1 \AA$ at the expense of the magnitude of Fe$\mathrm{N}_{\mathrm{p}}$ shell. With reference to Fe foil. this new peak is assigned 


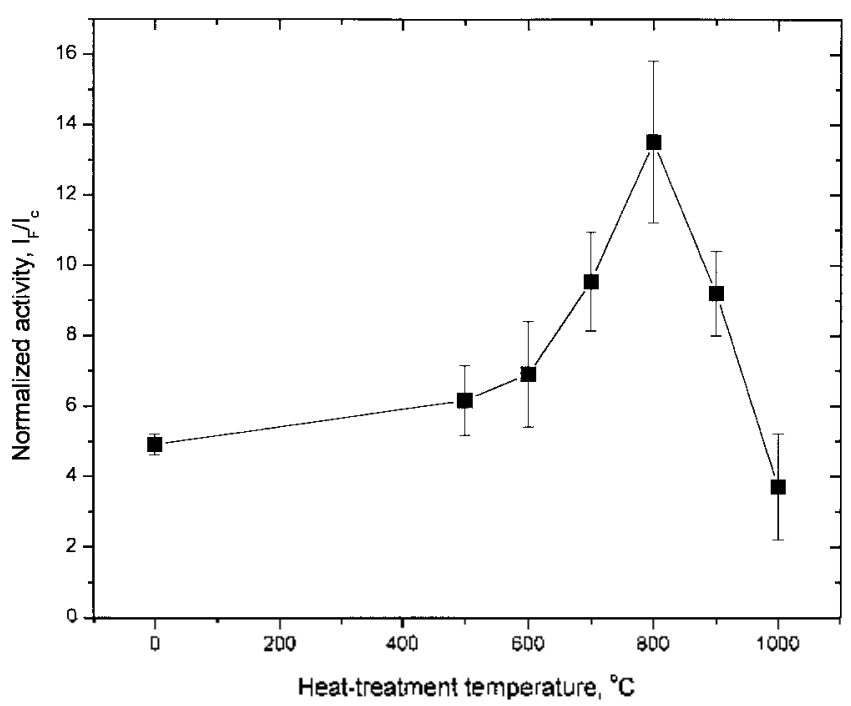

Figure 2. Normalized activities for the nitrite reduction expressed by $I_{F} / I_{C}$ as a function of heat-treatment temperature. $I_{F}$ and $I_{C}$ are faradaic and charging currents, respectively. Is was measured at $+0.1 \mathrm{~V}$ is Ag/AgCl$/ \mathrm{KCl}$ at' with $\mathrm{FePc}$ on the surface.

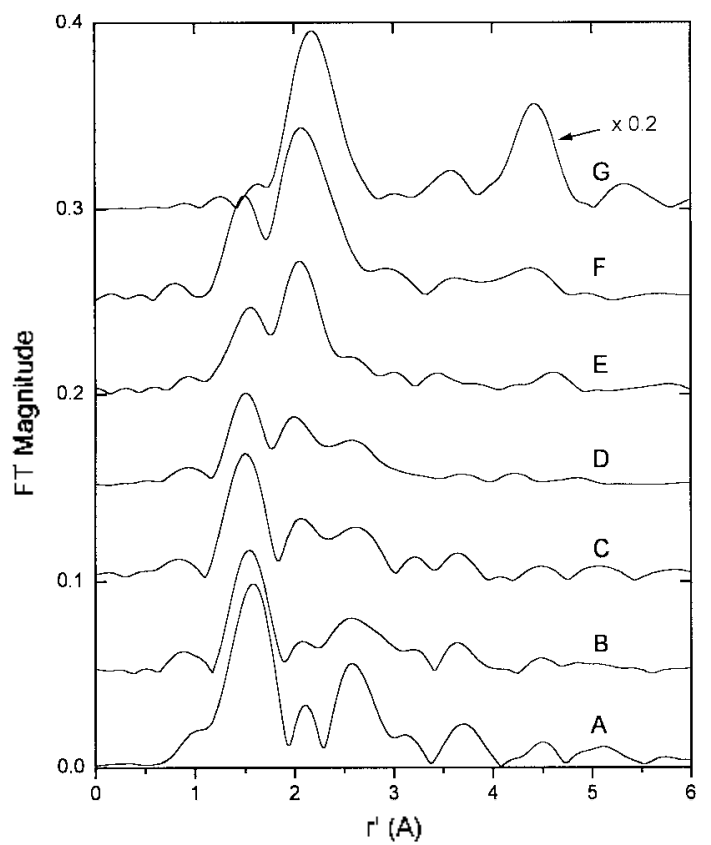

Figure 3. Fourier-transformed spectra of unleat-treated (A) and heat-treated $\mathrm{FePc}$ at 600 (B), 700 (C), 800 (D), 900 (E), and 1000 ${ }^{\circ} \mathrm{C}(\mathrm{F})$. Curve $\mathrm{G}$ is $\mathrm{FT}$ spectrum of iron foil for comparison.

to the Fe-Fe shell. It is peculiar that the highest activity is found at $800^{\circ} \mathrm{C}$. At this temperature. iron exists either as $\mathrm{Fe}$ $\mathrm{N}$ complex or as a form of small iron clusters. both of which exhibit catalytic activities. This means $\mathrm{Fe}-\mathrm{N}_{4}$ structure is not an absolute requisite for activity. While only $\mathrm{Fe}-\mathrm{N}_{4}$ structure is responsible for the unheat-treated sample, both $\mathrm{Fe}-\mathrm{N}_{\mathrm{x}}$ and metallic iron clusters play roles in exhibiting catalytic activities. The decreased activity above $800{ }^{\circ} \mathrm{C}$, despite the formation of metallic iron, can be attributed to the formation of larger iron clusters. It is well known that the sintering effect of heat-treatment at higher temperatures leads to the larger metallic particles. According to Tourillon et at. ${ }^{15}$ larger metallic clusters lose catalytic activities for the oxygen reduction. The same argument may apply to the nitrite case. Although it is not possible to estimate the size of the clusters from EXAFS analysis, the relative amount of metal cluster was shown to increase from fitting the first two peaks in FT spectra. The ratio of coordination numbers for $\mathrm{Fe}-\mathrm{Fe}$ to that for $\mathrm{Fe}-\mathrm{N}$ increased from 0.25 at $800^{\circ} \mathrm{C}$ to 1.5 at $1000^{\circ} \mathrm{C}$. The exact size of iron particles is not certain at the moment. however. This result is quite contrary to the case of $\left(\mathrm{Fe} \mathrm{Pc}_{2} \mathrm{O}\right.$. where the catalytic activity reaches almost zero at $1000^{\circ} \mathrm{C}$. But FePc still shows appreciable current even at $1000{ }^{\circ} \mathrm{C}$. There coexist both iron clusters and the Fe- $\mathrm{N}_{\mathrm{x}}$ structure when the samples were heat-treated above $c a .700$ ${ }^{\circ} \mathrm{C}$. The reason why the best activity is achieved at $800^{\circ} \mathrm{C}$ in our case is that the adequate size of metallic iron clusters are formed at this temperature. It may be concluded. therefore, that the $\mathrm{Fe}-\mathrm{N}_{4}$ structure is not essential to maintain the catalytic activity but the best electrocatalyst could be prepared by any means to give the adequate size of iron clusters.

Acknowledgment. The authors wish to acknowledge the funancial support of the Korean Research Foundation made in the program year of 1998. We thank Mr. H. J. Choi for the assistance during the experiments. Experiments at PLS were supported in part by MOST and POSCO.

\section{References}

1. See, for example, Bockris, J. O'M ; Reddy, A. K. N. Hodem Electrochentism. Plenum Press: New York. U. S. A.. 1970: Ch. 11.

2. Kovacic. P. Bioelect. Bioenerg. 1996. 39. 155.

3. Styder. S. H.: Bredt. D. S. Sci. Am. (May) 1992. 68.

4. Burdett. A. L.: Lowenstein. C. J.; Bredt. D. S.; Chang. T. S. K.; Snyder. S. H. Science 1992, 257. 401.

5. Rhodes. M. R.: Barley, M. H.: Meyer, T. J. Horg. Chem 1991, 30. 629

6. Barley. M. H.: Rhodes. M. R.: Meyer. T. T. horg Chent 1987. 26. 1746.

7. Barley, M. H.: Takeuchi, K. J:- Meyer, T. J. J. Am. Chem. Soc 1986. 108,5876

8. Hwang. D. Y.: Park, J; Kim, S. Bull. Korean Chem. Soc. 1998. 19. 795 .

9. Ha. S. Y.: Kiml. S. J. Electroanal, Chent 1999. 168.131.

10. Nikolov. I.: Vitanov. I.: Najdetov. V.: Milusheva. T.: Vitanov. T. , Appl. Electrochem. 1997, 27.77.

11. Jahnke. H:; Schoenborn. M.; Zimmermann, G. Top. Cur: Chem. 1976. 61,133

12. Lefevre. M.: Dodelet. T. P.: Bertrand. P. J. Phos Chem. B 2000. 10t. 11238.

13. van Wingerden. B.: van Veen. T. A. R.: Mensch. C. T. T. J. Chent. Soc. Faraday Trans. 1 1988. 84, 65 .

14. Martins Alves, M. C.: Dodelet, J. P.: Guay, D.; Ladouceur. M.: Tourillon G. J. Phys. Chem. 1992, 96, 10998.

15. Martins Alves. M. C.: Tourillon. G. J. Phus. Chem. 1996. 100. 7566. 